\title{
Certification in Critical Care Nursing
}

National Cancer Institute

\section{Source}

National Cancer Institute. Certification in Critical Care Nursing. NCI Thesaurus. Code C71298.

The process of obtaining certification in critical care nursing as granted by the American Association of Critical-Care Nurses (AACN) Certification Corporation. Registered nurses who have not achieved CCRN certification status or whose CCRN status has lapsed are not authorized to use the CCRN credential. 